\title{
GUERRA DE MAÇÃS E SEUS DESDOBRAMENTOS: A ESCOLA COMO PAISAGEM PERFORMATIVA
}

\author{
Marina Marcondes Machado
}

RESUMO: O artigo lança semeadura para macieiras — imagem de reparação para uma guerra de maçãs ocorrida em uma escola pública brasileira, episódio disparador do texto, cuja referência central é a performatividade cotidiana e extracotidiana na educação e suas possibilidades hermenêuticas: leitura de si, do outro e do mundo compartilhado. A aposta feita é de ocupação dos espaços escolares como espaço convivial dos seres viventes: locais de pertença e de vitalidade, bem como fórum de conversas sobre múltiplos assuntos, incluindo a doença, a violência e a morte.

Palavras-chave: Educação. Escola. Performance. Criança. Professor.

\section{War of apples and its developments: the school as a performative landscape}

ABSTRACT: The article scatters seeding for apple trees, an image that refers to a war of apples that took place in a Brazilian public school. This episode is the trigger for the text, whose central reference is the daily and non-daily performativity in education and its hermeneutic possibilities: reading of one's self, of the other, and of the shared world. The text argues for the occupation of school spaces as the convivial space of living creatures: sites of belonging and vitality, as well as a forum for talks on multiple issues, including disease, violence, and death.

Keywords: Education. School. Performance. Child. Teacher.

${ }^{1}$ Universidade Federal de Minas Gerais - Belo Horizonte (MG), Brasil. E-mail: mmjm@uol.com.br DOI: $10.1590 /$ CC0101-32622017168669 


\title{
INTRODUÇÃO: GUERRA DE MAÇÃS COMO PRÓLOGO A UMA PROFECIA
}

\begin{abstract}
Num dia de trabalho como todos os outros, naquela escola pública de período integral, onde as atividades se dividem em aulas curriculares e, de tarde, oficinas, logo após o almoço das 600 crianças que ali convivem aconteceu uma impressionante "guerra de maçâs". Pequenas maçâs cortadas ao meio servidas como sobremesa foram inicialmente atiradas por alguns poucos alunos entre si, e essa atitude contaminou a todos os outros no refeitório e pátio de tal forma que os adultos presentes nada puderam fazer. Minutos depois, todos em fila para a volta às classes, e o chão coberto de maçâs destruídas, como professora percebi nesse cenário o aviso de haver uma outra batalha: a incompreensão e insatisfação de todos em pertencer e viver nesse lugar autoritário, onde a expressão de cada um é tolhida pelo silenciamento.
\end{abstract}

Mônica Marcondes (depoimento a pedido nosso) ${ }^{1}$

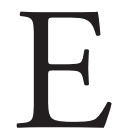

sta reflexão surge a partir do episódio narrado — uma guerra de maçâs no final do horário coletivo de almoço — , ocorrido em uma escola estadual de Ensino Fundamental I na cidade de São Paulo, entre 2010 e 2011, e conversará com o leitor acerca das possibilidades de compreensão, concreta e simbólica, desse ato performativo (MACHADO, 2015) experienciado por crianças e jovens púberes. Considero que as crianças, por meio da violência entre pares e do desperdício da merenda escolar gratuitamente distribuída, dizem algo aos adultos. O uso de maçãs como bombas ou pedras talvez possa traduzir-se por pobreza imaginativa, incapacidade para brincar de modo "livre e criativo", como queria Winnicott (1994), e dificuldade para a metáfora e a mimesis, nos termos de Paul Ricouer (2012): fim da simbologia da maçã; profanação da árvore do conhecimento unificador, assunção da árvore do conhecimento desagregador. Uma leitura inicial acerca dos meninos e meninas da guerra de maçấs consideraria que eles se mostraram empobrecidos, literais, empedernidos em um modo de ser que não simboliza. Algo revelado pelo uso daquilo que se tinha à máo para uma solução 
rápida e imediata, via curta (para extravasar raiva e impulso agressivo?): lançar a maçã na direção do outro. Outro com o qual não faço trocas, com quem nem de longe imagino transformação, muito menos novos mundos possíveis. Bato antes que me batam. Atiro a primeira maçã.

Há que habitar melhor o mundo; como fazê-lo?

Esta reflexão partirá do meu campo de trabalho, o território artístico; inicio com o risco de um caminho existencial e relacional traçado de tal maneira que arte não poderá ser sinônimo de "projeto social”, benevolência ou adestramento. Arte é território potente de habitarmos o espaço corpo próprio e coabitarmos o espaço mundo compartilhado. Arte é uma possibilidade relacional que espacializa imaginaçóes. Arte é criação de muitos e muitos mundos: possíveis e incompossíveis. Arte não é maneira de "tirar o menino da rua", "tirar o menino das drogas": arte é algo que pode estar na intensa experiência da rua e que dialoga, indubitavelmente, com o recorrente desejo humano de drogar-se, anestesiar-se, jogar fora o alimento.

Urge outra lógica no pensamento adulto, daqueles que formulam políticas públicas, dos que dirigem escolas, dos que ensinam teatro, artes visuais, música e dança, daqueles que formam jovens nas graduaçôes em licenciaturas pelo Brasil afora: lógica repensada a partir do que Bachelard (apud BARBOSA, 1995) chamaria de "razão imaginante"; lógica que não almeja "atividades adequadas a faixas etárias", mas, antes, propóe atos performativos que (re)ocupem o espaço escolar. Lógica contemporânea para possibilitar a potência da performatividade cotidiana e extracotidiana dos viventes em seus espaços conviviais.

Por mencionar espacialidades, e se os meninos tivessem macieiras para subir e brincar, e pudessem colher seu fruto? E se a merenda fosse composta de geleia de maçã, feita por eles mesmos, em cozinha compartilhada na escola? Como e por que as escolas públicas se assemelham a prisóes, e o comportamento de crianças e jovens ao de pessoas em privação de liberdade?

A guerra de maçãs presentificou um motim, uma rebeliāo, um exercício de poder de um grupo de crianças que, tal qual presos em condiçóes precárias, nada mais teriam a perder.

E se sentissem, sinceramente, que perder as maçãs seria penoso? 
E se socassem bons e grandes nacos de argila e modelassem, com o barro, frutas imaginadas e pequenas árvores bonsai, conhecidas como árvores da sorte?

Diz o Dicionário de Símbolos - referência central neste artigo - , na frase final para o verbete "maçā": "a maçã seria o símbolo desse conhecimento [a via dos desejos terrestres e a da espiritualidade] e a colocação de uma necessidade: a de escolher" (1997, p. 573). No entanto, na guerra acontecida naquela escola, a maçá tornou-se arma — ligação direta, via curta - , era o que se tinha à mão. Não havia escolha. A macieira não significava, como pretende o Dicionário de Símbolos, "árvore de Outro Mundo”. A maçã foi arma para destruir o Mesmo Mundo: mesmo dia, mesma rotina, mesmo horizonte sem árvores. Em contos sagrados, a maçã servia como prólogo a uma profecia; profanada e tornada pedra, na guerra da escola contemporânea, a maçã presentificou o eterno retorno da crise da educação pública no Brasil.

Proponho à comunidade adulta imaginar o epílogo para a guerra de maçãs de modo que outras narrativas se instalem. Para tal, o primeiro passo é desnaturalizar o discurso cuja frase-síntese é: "os meninos estão assim”. Pois poderiam estar diferentes! Mudança que depende de uma moldura, institucional e relacional, marchetada por adultos, que já se encontravam no mundo quando as crianças nasceram (ARENDT, 2014). Conversaremos com concepçóes elaboradas por Hannah Arendt no clássico ensaio $A$ crise na educação, publicado originalmente no final da década de 1950, cujo tema central são as novas pedagogias nos Estados Unidos e as respectivas prerrogativas éticas, estéticas e políticas.

Arendt (2014) é rigorosa frente ao papel dos adultos e afirmativa acerca de um tipo de atitude necessária diante da natalidade, ou seja, face ao fato de "[...] todos nós virmos ao mundo ao nascermos e de ser o mundo constantemente renovado mediante o nascimento". A filósofa define o ato de educar como um lugar

[...] onde decidimos se amamos nossas crianças o bastante para não as expulsar do nosso mundo e abandoná-las a seus próprios recursos, e tampouco arrancar de suas máos a oportunidade de empreender alguma coisa nova e imprevista para nós, preparando-as em vez 
disso com antecedência para a tarefa de renovar um mundo comum (ARENDT, 2014, p. 247).

\section{Pois então como acolhê-las?}

E como apresentar-lhes a concretude e a simbologia das maçás, dentre tantos outros assuntos?

Nunca mais como pomo da discórdia, mas como fruto da Árvore da Vida, comer dele significaria, como nos aponta o Dicionário de Simbolos, aprendizado de escolha e de renovação. Pomares de macieiras serão paisagens performativas, cenários de casas na árvore para os meninos e meninas aprenderem a usar tesouras, canivetes e cordas. Não haverá facadas nem enforcamento, apenas presença das forças do bem e do mal, circulando por entre tintas e papéis, panos, livros, bolas e bonecas, fitas e botóes, sementes e panelinhas, mais tarde torno de barro e queima das obras criadas - uso criativo e humanizador da terra e do fogo.

Todos conectados à potência do brincar e, antes de dormir, comerão três maçãs, tal como proposto na simbologia do Dicionário: "a pessoa que as consumir não mais sente fome, nem sede, nem dor, nem doença, e elas nunca diminuem” (CHEVALIER; GHEERBRANT, 1997, p. 572). Retomada da narrativa que nos constitui. Vínculo. Mistura de ficção e história, identidade narrativa (RICOUER, 2010) que habita um terceiro espaço (WINNICOTT, 1978) — área do consolo, espaço de ilusão —, lugar passível de ser (re)criado por crianças e jovens, rumo a bons começos, na direçáo de construir e compartilhar projetos de vida como parte intrínseca de suas biografias: habitar as possibilidades mais possíveis, e criar brechas, frestas e rachaduras nos mundos de vida (e morte), para revelar discursividade e ação, de si com o outro no mundo.

Para propor a meninos e meninas que guerreiam com maçãs uma virada, uma mudança possível na direção do brincar, imaginar e criar, ou seja, uma caminhada na direção da saúde psíquica, será necessária uma radical reviravolta nos modos de formação de novos professores. Vale frisar a necessidade premente de reviravolta na formação dos professores em geral, isto é, não apenas dos adultos artistas educadores (meu âmbito de atuação e estudo), para enxergarmos uma espécie de efeito bumerangue, na direção de mudanças relacionais. Aqui, o foco 
residirá nas possibilidades performativas que permeiam a educação estética: em especial a construção conjunta, lenta e minuciosa, entre adultos e crianças, da capacidade para ficcionalizar como modo de compreender a si mesmo, ao outro, e inserir-se no mundo compartilhado. Será nesta chave que a guerra de maçâs poderá ser reinterpretada: de modo aberto e polissêmico.

\section{DRAMATURGIAS DA ESPACIALIDADE COTIDIANA NA ESCOLA}

Os espaços comuns na escola onde ocorreu a guerra de maçás apresentavam-se muito pouco hospitaleiros, nada convidativos para jogos, brincadeiras e convívio: espacialidade, portanto, providencial para aquela qualidade de performance dos alunos. Estive lá como voluntária por um semestre, trabalhando com crianças do primeiro ano do Ensino Fundamental (uma hora semanal com encontros que propunham brincadeiras e teatralidade, depois de saber do evento da guerra de maçâs). Assim, permito-me descrevê-los.

Embora a estrutura da escola, em período integral, abarcasse oficinas, pouco se via pelo espaço algo que pudéssemos nomear processos ou produtos artísticos. Marcas próprias dos alunos, apenas em pequenos varais, na sala de aula de professoras que se importavam com isso, tímida e individualmente. Havia também a sala de artes, onde aconteciam aulas regulares de artes visuais; no entanto, a apropriação do espaço escolar pelos alunos mostrava-se praticamente nula. E, especialmente no momento do final do almoço, não só o espaço era "terra de ninguém", como também o tempo "livre" não podia ser vivido com a atividade mais corriqueira (e interessante) das culturas da infância e juventude: o brincar.

Os alunos que aderiram à guerra de maçãs estavam no momento final do almoço. Intervalo tenso, temporalidade vivida em uma espacialidade extremamente árida: escola sem pátio, sem terra, sem brinquedos para subir e descer ou campinho para jogar futebol, e com muitas regras do que "não pode" ser feito. A quadra, por exemplo, ficava trancada, só podendo ser utilizada nas aulas de Educação Física, na presença do professor da disciplina, guardião das chaves. 
O horário de almoço marcava a transição de turnos dos professores — os educadores de sala de aula (que trabalhavam pela manhã) e os de oficinas (que trabalhavam pela tarde) — , momento interessante e promissor para o surgimento e usufruto de entre-lugares, mas que se mostrava como um tempo extremamente delicado, no qual crianças e jovens ficavam aos cuidados dos assim chamados "inspetores de alunos". Segundo a autora do relato de nossa epígrafe inicial, a inusitada guerra de maçấs causou tamanha perplexidade que os adultos assistiram a ela sem esboçar reação.

Documentos curriculares trabalham com a elaboração de propositivas, desde a mais tenra infância, com base na quadrangulação entre tempos/espaços/materiais/interaçóes. Se essas palavras saíssem do papel da diretriz educacional para pular em uma espiral imaginada, as interaçóes se teceriam nos fios de relações, temporalidades e espacialidades, em um tear táo interessante quanto fossem as pessoas que os tecessem, suas experiências temporais e a ocupação dos lugares. Assim, se configuraria uma escola interessante e interessada: espaço de pertença e de saúde, bem como lugar de rodas de conversa sobre a doença.

Desenvolvo a noção de dramaturgia, hoje, como algo não necessariamente dito ou escrito, mas imagético e fronteiriço entre a realidade compartilhada e a capacidade ficcional de cada ser vivente. Nessa ótica, a espacialidade cotidiana nos apresenta, por si mesma, uma paisagem de dramaturgias possíveis, iluminada por improviso e risco: riqueza em conflitos e em intersubjetividades. Minha percepção é de que o campo teatral constitui um terreno privilegiado para que a vida se enriqueça de narrativas múltiplas e ficcionalidades: seja na teatralidade já dada por papéis e personagens com suas máscaras sociais, seja por meio da riqueza que o brincar de faz de conta, de recriar situaçôes, de tornar-se outro, permanecendo si mesmo, que a capacidade humana de mimesis nos proporciona - com a qual o teatro se contagia, na qual o teatro mergulha, emerge e submerge. A instauraçáo de novos minimundos, de acontecimento compartilhado em convívio, é própria também da arte contemporânea. Happenings, instalaçóes, performances, desde a primeira metade do século XX, mostraram-se ritos de questionamento e inovação: são antiestruturas 
(TURNER, 1974), esboços iniciais, ainda que rudes, de contestação das formas normativas, que podem anunciar novas organizaçóes, algo desdobrado na arte visual fora da galeria, o teatro acontecendo fora do teatro, a propositiva de escuta das múltiplas paisagens sonoras, a atenção à corporalidade de todos os tipos de transeuntes na vida cotidiana ordinária etc.

Adultos convidados a adentrar o território da arte, a subverter a ordem das cadeiras da sala de aula, das mesas do refeitório, do cadeado que tranca a quadra no horário de intervalo, talvez pudessem responder à guerra de maçãs de outro modo que não o silêncio paralisado. Para que outras respostas surgissem, os educadores haveriam de projetar e habitar outras maneiras de ser e estar nos seus espaços de trabalho - as escolas. Sugiro que essas outras maneiras possam ser antiestruturas que anunciariam novas futuras estruturas — como propôs Victor Turner (1974) —, em um ciclo para o "drama social" que se vitaliza com o comportamento restaurado, elaboração humana de elementos antes considerados ruidosos ou desviantes.

\section{CORPORALIDADES EM PORTÕES TRANCADOS}

Uma menina Uma menina igual a mil

Que não está nem aí Tivesse a vida pra escolher E era talvez ser distraída

$\mathrm{O}$ que ela mais queria ser

Ah se eu pudesse não cantar

Esta absurda melodia Pra uma criança assim caída Uma menina do Brasil Que não está nem aí Uma menina igual a mil

Do morro do Tuiuti

Chico Buarque 
Embora composta na segunda metade da década de 1980, a canção permanece atual. Retrata, com humor e ironia, dois modos de ser da criança e da jovem brasileira: não estar nem aí e querer ser distraída - algo interpretado aqui como uma corporalidade empedernida, entediada, indiferente. Jogar maçás uns nos outros pode pertencer a um inventário de açóes da "criança assim caída". Desse modo, uma "absurda melodia” foi ouvida não apenas no morro do Tuiuti, no Rio de Janeiro, mas também em uma escola da cidade de São Paulo, já no século XXI.

Como conversar e propor algo diante de corporalidades indiferentes? Não cantar mais a "absurda melodia" implica em ouvir, criar, dedilhar, cantar outras cançóes. Talvez, partindo inicialmente de novas paisagens sonoras (SCHAFER, 1992) para crianças pequenas, imaginaremos repertórios para o redesenho necessário das relaçóes escolares ao longo de toda a infância e juventude: um projeto que precisa dar-se entre adultos, na direção do ato performativo, conectar-nos a noçóes tais como o corpo encarnado, o onirismo, a experiência liminal (TURNER, 1974), termos que levem a redesenhos curriculares em diálogo com a arte contemporânea e com o campo híbrido da performance.

Seria pauta, em espaços de educação adulta, trabalhar com os pais e tutores a possibilidade da escola ser um lugar de pertencimento e troca. Funcionários também precisam ser chamados para a composição de novas melodias e, em especial, para além dos alunos, é claro, os gestores e os professores (seja o ruído que for!).

Uma escola em outra afinação só será possível quando a comunidade adulta estabelecer diálogo e trânsito livre entre docentes e discentes; adultos, crianças, jovens e pais; funcionários e gestores. Haveria um par complementar àquilo que concebi como "criança performer" (MACHADO, 2010; 2011; 2015): um adulto pronto para responder à corporalidade da criança com a sua própria, na busca de trocas entre gesto e palavra. Prontidáo não lapidada em cursos teóricos, treinamento ou formação: algo relacional e construído, pacienciosamente, na concretude dos mundos de vida.

No olhar aqui apresentado, o campo das artes há de semear a vida, bem como o debate sobre a morte. Experienciar nossos fantasmas: vividos, encarnados, corporificados em ciclos de alegria e luto; performar o "isso" que nos dá a condição de ser (DOLTO, 1984) 
por meio da expressividade de nossas corporalidades, teatralidades, musicalidades e espacialidades. No imaginado currículo em espiral (MACHADO, 2012), criado à sombra das macieiras, acontecerão rodas de choro, muito samba e rock'n'roll; chuva, suor e lágrimas; escuta, conversas, debate e troca; acolhimento da comunidade adulta às crianças e jovens que chegam ao mundo de vida escolar - lugar que habitarão por longo tempo —-, espaço pré-político, segundo Hannah Arendt, que concebe o âmbito político como próprio da sociedade adulta (ARENDT, 2014).

\section{MATERIALIDADE DO MUNDO: USO CRIATIVO E HUMANIZADOR DA TERRA, DO FOGO, DA ÁGUA E DO AR}

Proponho ao leitor marchetar comigo novas molduras para um mesmo quadro, o da educação pública brasileira, de volta ao que o psicanalista Winnicott (1978) nomeou "bom começo", em nome das possibilidades de escolha (não apenas a via curta — a saber, jogar a maçã). Recorro aqui a um aprendizado criativo obtido na convivência com o diretor teatral Ilo Krugli e os professores artistas da Casa do Ventoforte, no início da década de 1980, em São Paulo. Fui marcada por dois anos e meio de formação naquele contexto inovador: Ilo vivia um momento de inventividade e seu trabalho tinha premissas interessantes, a partir de seus estudos sobre o pensamento e a obra da Dra. Nise da Silveira, psiquiatra responsável por ateliês de arte instalados em um manicômio público do Rio de Janeiro. Segundo Ilo, Dra. Nise definia arte como depoimento: definição que se faz pano de fundo deste texto, evocando a identidade narrativa que habita um terceiro espaço, mescla de noçóes preconizadas por Ricouer (2010) e Winnicott (1994).

Hoje amadureço a experiência de juventude com Ilo Krugli ao perceber como ela pode ser recheada pela leitura e pelo estudo das Poéticas de Gaston Bachelard (1996; 1998), em diálogo com o momento pré-socrático da história da filosofia. Revisito espacialidades: a proposta de Ilo era de que as memórias de infância dos atores em formação se misturassem com um trabalho, original e único, de ocupação de uma 
sala com quatro cantos performados por nós com imagens vividas de cada elemento - água, fogo, terra e ar. Trinta anos mais tarde, agora na docência universitária, reativo as memórias e depuro aquele modo de formar atores e artistas educadores. Esboço a retomada do que enxergo retrospectivamente como uma formação para as artes na contemporaneidade, de modo sensível e concomitantemente enraizado em algo "velho", ancestral: as imaginaçóes humanas dos quatro elementos água, fogo, terra e ar.

Para que o pomar de maçãs fosse estabelecido na escola da guerra de maçãs, haveríamos de ter chão de terra, água para as sementes (restos da guerra de maçâs?!), ar para a fotossíntese, fogo como calor do sol que completa as necessidades básicas do cultivo de macieiras. No pomar de hoje, visualizem um ateliê de artes, no qual adultos (artistas educadores, professores performers) saibam propor coisas para se fazer: construir, brincar, desarmar, tocar, subir e descer, desenhar, pintar, performar!

Em escolas com crianças um pouco maiores, poderemos ter um torno e um forno próprio para a queima da argila; em escolas com crianças menores, imaginemos um forno a lenha à altura dos alunos, que aprenderiam, na companhia de adultos que sabem cozinhar, a fazer torta e purê de maçã, maçã caramelada — troca do arremesso de maçãs pela feitura, e fruição, das maçấs do amor das festas juninas e dos parques de diversão.

Pensar diferente implica sonhar. Sonhar espacialidades, performatividades, novas maneiras de ocupar o espaço e o tempo escolar e, principalmente, novas relaçóes adulto-criança, sem deixar de lado a tradição dos campos do conhecimento, e a inevitável — e necessária — identificação dos adultos com o que Arendt aponta como conservadorismo, "no sentido de conservação, que faz parte da atividade educacional, cuja tarefa é sempre abrigar e proteger alguma coisa" (ARENDT, 2014, p. 242). Nessa chave, os adultos que presenciaram a guerra de maçãs teriam algo a dizer e algo a fazer — não em termos de famigeradas broncas ou castigos, mas da autorreflexão: compreender o ponto de vista das crianças e dos jovens que culminou no ato de jogar maçãs uns nos outros e expressar o ponto de vista adulto - em nome da necessidade vital de comer, em nome do dinheiro público gasto em merendas, em nome da conversa, nesse caso necessária, sobre a fome e a vontade de comer: "Você tem fome de quê??" 


\section{PESSOAS, SUAS MEMÓRIAS E PROJETOS DE VIDA: TÔNICA PARA UMA FORMAÇÃO}

Nunca haverá soluçóes fáceis para as mazelas de uma sociedade em crise. Caminhos, percursos, trilhas, pontes, gambiarras, pedras e grama, mato no pátio da escola, plantar árvores em terreno árido e antigo.

Propus, como mote textual, imaginarmos coletivamente uma espacialidade rica em macieiras: concreta e simbolicamente. Mudanças são favorecidas diante da assunção do fracasso e da sensação de obsolescência: que expressão terrivelmente contemporânea! No modo de ser "não estar nem aî", falta pertença e pré-ocupação — concerning, para Winnicott $(1978 ; 1994)$. Para instigar pertença e instaurar pré-ocupação, faz-se necessário, também segundo Winnicott (1994), um brincar originário, dado por ciclos de alegria e luto (DOLTO, 1984), que conduzirá as capacidades humanas nas relaçóes iniciais. As reminiscências dos brincares, ao longo dos anos, transformam-se em fazeres artísticos - ou, ainda, em atos performativos. Adultos capazes de educar com amorosidade e significatividade conduzirão as crianças a habitarem a vida que vale a pena ser vivida. Habitar o próprio corpo: ser. Para depois fazer ensinamento do psicanalista Winnicott (1994).

Novas ocupaçóes do mesmo, produção de suco de maçã, geleia e salada de frutas... que, para serem inventadas, evocam um campo seminal de interesse, pré-ocupação mútua, relaçôes cuidadosamente construídas de modo a propiciar experiências totais, performadas tal como convida o teatro contemporâneo: um modus operandi colaborativo, em busca de relaçóes horizontais e copertença. Como fazê-lo? Possibilitando novos modos de ser e estar, nas mesmas categorias (talvez famigeradas) tão queridas pelos projetos pedagógicos da Educação Infantil ao Ensino Médio e à Educação de Jovens e Adultos: tempos, espaços, materiais e interações.

Os tempos da rotina escolar se farão temporalidade vivida como fluxo de conhecimento, criação e compartilhamento; os espaços serão espacialidades ricas em imaginaçóes, habitadas e experienciadas com jogos e brincadeiras recriados a cada agrupamento de idades, em propostas artísticas e científicas que dialoguem com projetos de futuro dos discentes e dos docentes; os materiais serão cuidadosamente 
escolhidos, em conexão com os tempos e espaços, com os desejos e necessidades, com possíveis experiências de entrelaçamento no passado, presente e futuro (seja pelos elementos da natureza, pela materialidade da vida mesma, pelas hipóteses das novas tecnologias etc.); e, quanto às interaçóes (relações adulto-criança, criança-criança, adulto-adulto), que ganhem densidade, interesse mútuo, convivialidade. A aposta adulta precisa ser no novo que a criança e o jovem são, encarnam e simbolizam, sem negar as tradiçóes:

Exatamente em benefício daquilo que é novo e revolucionário em cada criança que a educação precisa ser conservadora. Ela deve preservar essa novidade e introduzi-la como algo novo em um mundo velho, que, por mais revolucionário que possa ser em suas açóes, é sempre, do ponto de vista da geraçáo seguinte, obsoleto e rente à destruiçẫo (ARENDT, 2014, p. 243).

O enriquecimento do imaginário do professor performer, ao longo dos anos de trabalho e formação, há que se dar em íntima relação com a importância do brincar: o brincar imaginativo, aquele que prescinde de brinquedos. Tais seriam os ingredientes para a formação de professores cuja escolha é o campo das artes, projeto contemporâneo e performativo: simplicidade; depoimentos, testemunhos e histórias de vida; significatividade (ou não) para a escolha, existencial, de ser professor; trabalhar a capacidade, de algum modo a ser ampliada pelo convívio em contextos formativos, para delinear projetos de vida afinados com a cotidianidade no espaço da escola em que se trabalha, junto a crianças e jovens, e em compartilhamento com os outros adultos daquele mundo de vida — pais, funcionários, gestores. A tônica pode ser a de uma formaçáo relacional, sem aparelhos e aparatos preconcebidos - despojamento no estilo "um banquinho, um violão" que consistiria em um fórum permanente de discussão e de processos do performar de si, com o outro no mundo, na metodologia work in process/ trabalho em processo - advinda das artes e que pode migrar para o campo educacional como um todo. Na formação aqui imaginada, não se faria uso da pedagogia dos "bons modelos" nem buscaríamos harmonia e espelhamento: aqui os adultos trabalharão, necessariamente, com a radicalidade das diferenças. Viva o rap, o hip-hop e o funk brasileiros! 


\section{EPÍLOGO: OUTRAS NARRATIVAS ACERCA DAS MAÇÃS}

Eu particularmente eu detestava a escola, desculpa a sinceridade, mas eu detestava a escola por ela ser um ambiente muito opressor [...], só que eu detesto a escola mas eu acho que quem faz a escola somos nós [...], porém, tipo eu falo que eu não gosto assim só que é a minha escola, sabe, tipo eu quero estar aqui, eu quero mudar esse costume chato dos professores entrarem aqui e jogarem qualquer coisa na lousa, porque a escola pode ser do jeito que for mas é um ambiente nosso que a gente tem que lutar por ele [...] (Depoimento de aluna da EE Maria José (SP) - apud CAMPOS; MEDEIROS; RIBEIRO, 2016)

No processo de escrita deste texto, durante o segundo semestre de 2015, algo novo surgiu no horizonte da educação pública brasileira, anunciando um (possível) inusitado epílogo para as guerras de maçâs: fato memorável, diferente, longe de quaisquer parâmetros anteriores. Refiro-me às ocupaçóes contra o processo de "reorganização" escolar proposto unilateralmente e sem discussão pública com os interessados (comunidade de alunos, pais, professores e funcionários) pela Secretaria da Educação do estado de São Paulo.

Acontecimento de autogestáo, protagonismo e inventividade, revelador de maturidade, capacidade política, estratégica e estética de crianças e jovens paulistas! Deu-se ali um fenômeno que Victor Turner (1974) denomina communitas - cuja potência é a de estabelecer um comportamento restaurado ou possibilitar a invenção de tradiçóes —, próprio de momentos extraordinários dos assim chamados "dramas sociais". Turner (1974) ensinou como seria importante focar os momentos de interrupção de papéis, para avançar nas discussôes sociais. Já Richard Schechner (apud CARLSON, 2010) aproximou o conceito de comportamento restaurado à performance, abrindo um rico campo de pesquisa que une as ciências sociais às artes. Nessa perspectiva, talvez a guerra de maçãs nos teria apresentado uma possível antiestrutura — a exemplo das insurreições - advinda da crise estabelecida no "drama social" do ensi- 
no público brasileiro. Adultos mais porosos à interpretação polissêmica daquele acontecimento poderiam enxergar seu potencial antiestrutural e ler a guerra de maçãs como situação liminal (TURNER, 1974), "imagem da performance como uma borda, uma margem, um lugar de negociação" (CARLSON, 2010, p. 30). A compreensão antropológica da guerra de maçãs possui em si uma espécie de natureza performática.

O livro Escolas de Luta (CAMPOS; MEDEIROS; RIBEIRO), recém-lançado pela Editora Veneta (São Paulo, 2016), conta a história das ocupaçóes de modo etnográfico e por meio da análise do discurso das partes envolvidas. Em meio a um emocionante e cortante relato dos acontecimentos, transcrevo aqui os dizeres de um procurador do Ministério Público, em entrevista dada aos autores:

Porque judicializar por judicializar é relativamente simples. Poderia ter feito desde o primeiro dia. Agora saber o que de fato é melhor dentro de um processo que tinha sua riqueza de discussáo, de gente indo pra dentro da escola pública, artista, gente doando aula, coisas acontecendo e talvez o que foi mais surpreendente pra mim, pessoalmente, que eu venho acompanhando e fazendo visitas às escolas desde 2011 foi essa sensação de que os alunos se sentiam... enfim, desejosos daquela escola, de uma escola melhor, mas daquela escola que era deles, né? Porque a sensação que a gente tem às vezes, a impressão é que você vai nas escolas públicas e ninguém tá aí com nada, que pra eles tanto fez como tanto faz e de repente você percebe que náo é bem isso. [...] quando se chega com um projeto desse tamanho de remanejar compulsoriamente milhares de alunos e tal, a gente testemunhou algumas manifestaçôes emocionadas. $\mathrm{Na}$ audiência de conciliação tinha um grupo da escola Castro Alves, acho... "Ah, é uma segunda casa, a gente não quer sair de lá", sabe? De relação aluno/professor. Então tudo isso a gente não podia desconsiderar como uma força que pudesse... resultar em alguma coisa melhor, de verdade. Porque a judicialização no começo poderia, de duas uma: [ou] determinar interrupção da reorganização e aí interromper toda e qualquer discussão sobre ela, que estava sendo feito. Você talvez não tives- 
se boa parte da mobilização que houve e da discussão que houve sobre a escola pública, e como se faz gestão democrática, como se implementa política pública educacional. Ou pior: poderia ter perdido e aí, uma decisão judicial: "Pode ter". Então... sem escuta social, sem identificar todos os interesses, acho que não era o caminho adequado (Ministério Público - entrevista em 03/02/2016 - CAMPOS; MEDEIROS; RIBEIRO, 2016, p. 274-5).

O que aconteceu foi uma incrível virada de mesa. Parte do alunado da escola pública brasileira revelou possuir vínculo, sentimento de pertença e amorosidade em relação a seus espaços escolares cotidianos. A comunidade de pais também surpreendeu pela compreensão da questão, participando na trama de corresponsabilidade e cuidado pelos espaços ocupados, cujo pano de fundo era a exigência de dignidade e escuta por parte do poder público. Crianças e jovens derrubaram um secretário de Educação(!) e mostraram-se sujeitos ativos, desenhistas de suas histórias de vida no modo contemporâneo (pelo uso das mídias digitais e redes sociais com propriedade e eficácia).

O livro citado também denuncia injustiças e perversidades por parte dos gestores das escolas e da Polícia Militar, bem como negligência da cobertura midiática mainstream sobre o que realmente estava acontecendo nas escolas ocupadas. É importante comentar a atitude unilateral do governo de Sáo Paulo, que agiu com truculência, violando e traindo o Estatuto da Criança e do Adolescente: negando, de modo absurdo, a noção de protagonismo infantil e juvenil.

O outro modo de habitar o mundo lá estava, latente, potente nos estudantes de luta. Alguns observadores nomearam os eventos como "a primavera secundarista".

Como formadora de professores de teatro, tenho poucas certezas - mas uma delas é sobre a força do ato performativo do adulto educador. Há um tipo de performatividade assim melhor definida: performar é habitar seu campo de trabalho e ser feliz nesse lugar. Agora, após o movimento de ocupaçáo das escolas, há que positivar a força do ato performativo (pré-)político de crianças e jovens: a riqueza da performatividade na paisagem da escola é inegável. 
Fica evidente, também, nos relatos do livro, a percepção de que, nos adultos educadores, há falta de humor e ancestralidade, de conversa direta e aberta com a realidade extramuros (para além das escolas, universidades, Secretarias de Educação) e severa inabilidade para o real protagonismo possível de crianças e jovens nos mundos de vida.

Precisamos compreender a complexidade da vida das crianças e jovens que experienciam o impulso de atirar frutas uns nos outros - e, (quiçá) alguns deles, anos mais tarde, se mostrarão capazes de protagonizar uma verdadeira revolução pautada na solidariedade e na potência de sua juventude?!

Quisemos entretecer tempos, espaços, materiais e interaçóes de modo espiral e brincante no tear de páginas deste texto. Por fim, reivindicamos como direito de todas as crianças e jovens no Brasil comer salada de frutas e brincar de frutaria de barro e papel machê. Arrumadas em prateleiras ou caídas no chão, lá estarão as maçãs de argila à espera de serem (des)arrumadas por brincadeiras imaginativas. E, do lado de cá, as maçãs para serem comidas. Que crianças e jovens - tendo comido bem - cantem expressivamente, corram, saltem, agachem-se, brinquem de estátua (sem nunca perder o dinamismo e o movimento); que se envolvam nos mais diferentes tipos de dança, escrevam prosa e poesia, ampliem seus referenciais em arte, ciência e humanidade, rumo aos mais diversos tipos de ocupação: desdobramentos da morada de si, com o outro, no mundo compartilhado.

\section{REFERÊNCIAS}

ARENDT, H. A crise na educação. In: Entre o passado e o futuro. São Paulo: Perspectiva, 2014.

CAMPOS, A.; MEDEIROS, J.; RIBEIRO, M. Escolas de Luta. São Paulo: Veneta, 2016.

CARLSON, M. Performance/Uma introdução crítica. Belo Horizonte: Editora da UFMG, 2010.

CHEVALIER, J.; GHEERBRANT, A. Dicionário de Simbolos. Rio de Janeiro: José Olympio Editores, 1997.

DOLTO, F. No jogo do desejo. Rio de Janeiro: Zahar Editores, 1984. 
HOLLANDA, C.B. Tantas Palavras/Chico Buarque. São Paulo: Companhia das Letras, 2006.

MACHADO, M. A criança é performer. Revista Educação \& Realidade. v. 35, n. 2, p. 115-137, maio/ago. 2010.

MACHADO, M.M. Só Rodapés: Um glossário de trinta termos definidos na espiral de minha poética própria. Revista Rascunhos. Uberlândia, v. 2, n. 1, p. 53-67, jan./jul. 2015a.

- Dez passos adultos na direção da criança performer. Anais do VI Congresso da ABRACE. 2010. Disponível em: http://www.portalabrace. org/vicongresso/pedagogia/Marina $\% 20$ Marcondes $\% 20$ Machado $\% 20$ -\%20Dez $\% 20$ Passos\%20Adultos\%20na\%20Dire\%E7\%E3o\%20da\%20 Crian\%E7a\%20Performer.pdf. Acesso em: 10 jun. 2016.

MALTA, A.; JANUÁRIO, A.; MEDEIROS, J.; RIBEIRO, M. As ocupaçôes das escolas em São Paulo (2015): autoritarismo burocrático, participação democrática e novas formas de luta social. Revista Fevereiro. \#9. Abril de 2016. Disponível em: http://www.revistafevereiro.com/pag.php?r=09\&t=12. Acesso em: 12 jun. 2016. RICOUER, P. Tempo e Narrativa. São Paulo: Editora WMF Martins Fontes, 2010. TURNER, V. O processo ritual. Estrutura e Antiestrutura. Petrópolis: Vozes, 1974. WINNICOTT, D.W. Textos Selecionados: da Pediatria à Psicanálise. Rio de Janeiro: Francisco Alves Editora, 1978. . Playing and Reality. Londres e Nova Iorque: Tavistock e Routledge, 1994.

\section{NOTAS}

1. Professora do Ensino Fundamental da rede pública de Sáo Paulo, poeta e fotógrafa.

2. Música de Arnaldo Antunes, Marcelo Fromer e Sérgio Britto, 1987.

Recebido em 04 de outubro de 2016.

Aprovado em 23 de fevereiro de 2017. 